\title{
Resistindo às pressões dos conservadorismos, apesar de tudo
}

\author{
Resisting the pressures of conservatism, despite everything
}

\author{
Luzinete Simões Minella $^{1}$ (id) 0000-0001-7953-7385 \\ Tânia Regina Oliveira Ramos ${ }^{1}$ \\ 0000-0002-2477-0419 \\ Mara Coelho de Souza Lago' \\ 0000-0001-5111-8699 \\ Cristina Scheibe Wolff' ${ }^{1}$ \\ 0000-0002-7315-1112 \\ 'Universidade Federal de Santa Catarina, Florianópolis, SC, Brasil. 88040-900
}

\section{$-$}

Este número da Revista Estudos Feministas dá continuidade ao debate sobre temas que têm sido objeto de discussão na academia e nos movimentos feministas, com ampla repercussão nas mídias e na sociedade em geral. A seção artigos inicia com a análise de questões instigantes: metas dos feminismos no contexto neoliberal; desigualdades de gênero na sucessão hereditária; especificidades do envelhecimento das mulheres; os direitos das mulheres à moradia, em particular na Espanha; uma revisão crítica sobre a construção do conceito de interseccionalidade; violências de gênero numa perspectiva interseccional; feminicídios no Brasil e no México; resistências femininas nos contextos de imigração; análise da trajetória de uma andarilha urbana.

Questões ligadas à maternidade e aos corpos das mulheres também são debatidas nos artigos posteriores: controle da natalidade e esterilizações compulsórias das imigrantes nos Estados Unidos; gramática moderna da maternidade; maternidades nos estudos feministas e da deficiência; reflexões sobre corpos que não devem ser instados a produzir desejos; partos e violências obstétricas; itinerários abortivos; um enfoque decolonial sobre menstruação; regulação do corpo feminino em antigo almanaque brasileiro de farmácia.

Finalizando esta seção, outras temáticas são apreciadas: corpo e transexualidade; situação das travestis e transexuais encarceradas no Ceará; AIDS em homens que fazem sexo com homens - amores e riscos; especificidades, sutilezas e moralidade no âmbito das saunas; concursos juninos em Belém do Pará e os regulamentos da cultura; juventude camponesa e a divisão sexual do trabalho no campo. Além desse expressivo conjunto de artigos, a seção Ensaios explora a transição das mulheres de objeto a sujeito do conhecimento e, na seção Ponto de Vista, divulgamos a entrevista realizada por Gabrielle Vivian Bittelbrun com Ana Gabriela Macedo sobre "Corpografias do feminino na literatura e na arte".

O Dossiê, organizado por Luciana Zucco, Vera Gasparetto e Isabel Maria Casimiro, aborda os feminismos afro-moçambicanos e se divide em duas partes. A primeira reúne seis artigos sobre vários temas candentes: uma análise sobre o papel da organização do Fórum Mulher no cenário político moçambicano; militância das cabo-verdianas no movimento independentista; lutas das mulheres contra o neoliberalismo e o patriarcalismo no contexto da Aids; as relações entre cultura, tradição e questões de gênero na feminização do HIV/SIDA; a participação das mulheres nos cursos de ciências, tecnologia, engenharia e matemática no ensino superior moçambicano; reflexões sobre o campo dos estudos de gênero em Moçambique. Na segunda parte, dedicada aos ativismos, foram incluídos três manifestos de importantes organizações de mulheres (Fórum Mulher (FM); Associação Sócio-Cultural Horizonte Azul (ASCHA) e o Fórum das Mulheres Rurais (FOMMUR)), além de uma entrevista com Isabel Maria Casimiro, uma das organizadoras do Dossiê, socióloga moçambicana, docente e pesquisadora do Centro de Estudos Africanos da Universidade Eduardo Mondlane em Maputo, Moçambique. 
O Dossiê colabora de modo significativo na preparação do terreno para a realização da $14^{a}$ edição do Congresso Mundos de Mulheres, Women's Worlds Congress, que se realizará nesta mesma Universidade entre os dias 21 e 24 de setembro de 2020. Lembramos que a próxima edição deste importante congresso internacional foi articulada durante o $13^{\circ}$ Mundos de Mulheres, que ocorreu no campus da UFSC, em Florianópolis, em parceria com a $11^{a}$ edição do Seminário Internacional Fazendo Gênero, entre os dias 30 de julho e 04 de agosto de 2017. Seguindo a tradição, a $14^{a}$ edição deste congresso pretende fortalecer o diálogo entre os ativismos e academia, num debate internacional sobre os desafios das mulheres, dos feminismos e do gênero. Conforme mencionamos no editorial do número anterior, parcerias entre universidades e movimentos de mulheres têm se encarregado da sua organização e uma Comissão Pró-Moçambique 2020 foi criada pelo Instituto de Estudos de Gênero (IEG/UFSC) para motivar e organizar a participação de uma representativa delegação nacional e internacional.

Também no editorial do número anterior observamos que entre os dias 26 e 31 de julho de 2020 realizaremos na Universidade Federal de Santa Catarina o Seminário Internacional Fazendo Gênero 12 - "Lugares de fala: direitos, diversidades, afetos". Evento interdisciplinar envolvendo pesquisadoras, estudantes, ativistas, artistas, professoras e interessadas nas questões que se organizam em rodas de conversa, mesas redondas, conferências, oficinas, atividades culturais, exposição de pôsteres, lançamentos de livros. O Fazendo Gênero 12 já conta com 192 Simpósios Temáticos aprovados.

A participação num evento desta natureza, com importante comprometimento das editorias da REF, seja na divulgação, seja nas futuras publicações, torna-se mais relevante diante dos retrocessos que os movimentos ligados aos direitos humanos em geral têm enfrentado à medida que visibilizará - através das falas e publicações - as lutas contra preconceitos, discriminações, racismos, violências físicas extremas e simbólicas, entre outros ataques (que, infelizmente, têm se tornado assustadoramente comuns) às mulheres, aos negros, aos indígenas, aos LGBTs, aos moradores de rua, às comunidades periféricas urbanas, aos trabalhadores sem terra e outros segmentos da população brasileira, bem como à linguagem, à arte, às políticas públicas. Eventos interdisciplinares que envolvem academia e movimentos sociais como os Fazendo Gênero constituem-se em significativas formas de resistência, em questões que se estendem para as leituras do porvir anunciadas nas sempre importantes resenhas de livros recentemente publicados.

No intuito de contrabalançar a desesperança diante de tantos retrocessos, muitos deles inimagináveis, aos quais temos nos referido constantemente e que ocupam boa parte dos noticiários locais e internacionais, destacamos neste editorial alguns exemplos de resistência representados por medidas que vêm sendo tomadas pelos movimentos e várias instituições no sentido de resistir às pressões dos conservadorismos extremos. Não apenas no dia 25 de novembro, Dia Internacional de Eliminação da Violência contra as Mulheres, mas durante os 16 dias de ativismos programados em várias cidades do país, os coletivos feministas desencadearam uma série de debates, manifestações, oficinas, palestras etc., dialogando sobre o tema com o público nas ruas, nas instituições, na academia (ONU MULHERES BRASIL, 2019). Não por acaso, os feminicídios, bem como os assassinatos frequentes das pessoas LGBTs, ocuparam boa parte da agenda dos movimentos, refletindo uma preocupação que vem aumentando na proporção do incremento desse tipo de violência extrema, capaz de impactar seriamente filhos, famílias de origem, vizinhos/ as, amigos/as.

Mais uma vez, os coletivos mostraram sua capacidade de organização e de reação à barbárie que continua recaindo sobre eles, uma das heranças mais perversas de uma sociedade patriarcal, racista, sexista, homofóbica, lesbofóbica. Nos países vizinhos, em meio às instabilidades políticas, os coletivos feministas também reagem às violências. Nesse mesmo período de ativismos, chamou atenção a expressiva manifestação das mulheres chilenas contra aquilo que chamam de "Estado estuprador", ou seja, um Estado patriarcal, ausente, conivente, incapaz de enfrentar os ataques que elas vêm sofrendo (Debora DINIZ; Giselle CARINO, 2019).

Vale a pena registrar também que no dia 04 de dezembro do corrente ano, após uma ação popular movida pelo advogado Hélio de Sousa Costa, provavelmente impulsionada pela repercussão negativa por parte da mídia e da sociedade civil, especialmente pelas organizações que representam o movimento negro, o juiz Emanuel José da Silva Guerra, da 18a Vara Federal do Ceará suspendeu, em despacho, a nomeação de Sérgio Camargo para a presidência da Fundação Palmares, em virtude de suas declarações no mínimo polêmicas, negando o racismo no Brasil. $O$ parecer do juiz considerou que as declarações, de amplo conhecimento público, contradizem a própria concepção da Fundação Palmares. Embora haja possibilidade de recurso por parte do nomeado, as fortes reações ao seu nome sinalizam que a tolerância da sociedade aos absurdos que todos os dias acontecem nesse país tem seus limites (Paulo Roberto NETTO, 2019).

Ressaltamos ainda que tem havido fortes reações, através dos órgãos de representação de docentes, como a Associação Nacional dos Dirigentes das Instituições Federais de Ensino Superior (ANDIFES), por parte da imprensa e de parlamentares através de requerimentos etc., às declarações 
do ministro da Educação, Abraham Weintraub, sobre a existência de "plantações extensivas de maconha" nas universidades federais e sobre o uso dos laboratórios de química para a produção de drogas. A Comissão de Educação da Câmara convocou o Ministro para explicar seus pontos de vista no dia 11 dezembro e a ANDIFES exige que ele apresente as provas de suas acusações. Tais declarações, em entrevista ao Jornal da Cidade, em novembro passado, se somam a uma série de outras igualmente absurdas, em particular contra o ensino superior (seu alvo preferencial - por que será?) e que vêm sendo amplamente divulgadas pela imprensa e rebatidas pelos mais diversos setores da sociedade civil (Mateus VARGAS, 2019).

Outra notícia que evidencia os avanços alcançados pelas nossas denúncias e resistências: após várias diligências, o policial militar Rodrigo José de Matos Soares, acusado de assassinar a menina Ágatha Vitória Sales Felix, de apenas 8 anos, com um tiro de fuzil em 20 de setembro no Complexo do Alemão, no Rio de Janeiro, foi denunciado pelo Ministério Público do Rio de Janeiro (MP-RJ), em 3 de dezembro, por homicídio qualificado. Caso seja condenado, o policial estará sujeito a cumprir entre 12 e 30 anos de prisão (Fausto MACEDO; Pepita ORTEGA, 2019). Sabemos que nada vai trazer a pequena Ágatha de volta. Sabemos também que dificilmente, algum dia, seus familiares encontrarão consolo. Podemos estar sendo demasiadas otimistas ao falar num alívio, quando há milhares de pendências na justiça sobre casos semelhantes e inclusive piores. Quando cenas de violência policial se repetem cotidianamente como, por exemplo, o assassinato dos nove jovens mortos durante uma perseguição policial ocorrida durante um baile funk na comunidade de Paraisópolis, em São Paulo, no dia 01 de dezembro de 2019 (CARTA CAPITAL, 2019). Mas o fato de o policial que assassinou Ágatha ter sido denunciado pelo menos sinaliza também os limites da tolerância em relação às assustadoras violências em geral e às crianças das periferias, em particular.

Tem sido possível também deslocar nosso olhar dos desmandos do poder executivo, para prestar atenção em algumas posições que o Congresso vem adotando frente a inúmeras propostas autoritárias, inclusive derrubando vetos assinados pelo presidente. Por exemplo, recentemente o presidente vetou a lei que obriga a presença de psicólogos e de assistentes sociais nas escolas públicas. Após muitos debates e diante das reações das/os educadoras/es, no dia 27 de novembro, o Congresso derrubou o veto. Dessa forma, foi retomado o projeto do ex-deputado José Carlos Elias (PTB), aprovado pelo plenário em setembro passado. Segundo este projeto, caberá ao Poder Público assegurar esse tipo de atendimento na rede pública de educação básica. Os psicólogos deverão estar vinculados ao Sistema Único de Saúde (SUS) e os assistentes sociais ao Serviço Único de Assistência Social (SUAS). Os sistemas de ensino, saúde e de assistência social terão o prazo de um ano para se ajustarem a essas normas após a publicação da lei (Ana Luiza BASILIO, 2019).

Recentemente o jornal O Estado de São Paulo divulgou que nove Medidas Provisórias (MPs) encaminhadas pelo governo foram derrubadas pelos parlamentares. Entre elas, constava a suspensão do desconto da contribuição sindical na folha salarial das empresas, fragilizando as organizações sindicais. A Medida causou enorme polêmica, organizações sindicais protestaram com veemência, o Congresso reagiu e, no final, a mesma vigorou por apenas quatro meses (Daniel WETERMAN, 2019).

Inúmeras outras marchas e contramarchas promovidas numa conjuntura de alta instabilidade política poderiam ser listadas. Num contexto de violação de direitos humanos, de ataques às universidades, aos princípios fundamentais da educação e da dignidade humana, de guerra às políticas de preservação do meio ambiente, às políticas científicas e tecnológicas através de cortes orçamentários e disseminação de inverdades, de ataques (ideológicos) à perspectiva de gênero, de criminalização dos movimentos sociais, em meio às declarações bizarras dos governantes, não podemos deixar de considerar a continuidade da REF, a edição deste número e, por extensão, a continuidade das revistas científicas no país, como um tipo de resistência que se junta àquelas que foram aqui brevemente listadas. Apesar de todos os ataques diários. Apesar da falta de apoio, de recursos. Apesar de tudo. Apesar de vocês. Apesar de você. Como a palavra cantada de Chico Buarque, o poeta e porta-voz de uma história do Brasil que não será apagada.

Os editoriais da REF, como já ressaltamos (Mara LAGO; Tânia RAMOS; Luzinete MINELLA; Cristina WOLFF, 2019), “... falam de seus objetivos, compromissos, apresentam os conteúdos de cada número publicado, e mais: traçam um panorama histórico de algumas circunstâncias pelas quais passa o país, nas análises das políticas que afetam as vidas" (p. 1) das mulheres e de toda a população brasileira. Neste número, frente à avalanche de notícias que é derramada pelas mídias virtuais especialmente, pelos jornais diários, revistas semanais, na desconstrução sistemática das políticas sociais construídas num regime capitalista liberal, ainda sem a exacerbação do neoliberalismo que assola não apenas o Brasil, na imposição do Estado mínimo, expansor ilimitado do fosso das desigualdades, tivemos que nos servir dessas referências diárias, semanais, buscando acompanhar a dinâmica de um panorama histórico do tempo presente em ebulição.

Este editorial buscava vias de esperança quando nos chegou a notícia da perda de companheira insubstituível, com o anúncio da morte de Nilcéa Freire. Mais uma perda irreparável, 
agora de uma feminista que protagonizou importantes conquistas nas lutas das mulheres brasileiras por uma sociedade mais justa para todas. Buscamos na postagem em rede social da professora e pesquisadora da UFRJ, Carla Rodrigues (2019), colaboradora da REF, as palavras certas para a justa homenagem, em nosso luto:

É verdade que a ministra Nilcéa Freire nos deixou muito cedo. Mas é verdade também que essa mulher teve uma trajetória extraordinária: como reitora da UERJ, foi pioneira na criação de cotas para pessoas negras; como titular da secretaria dos Direitos das Mulheres, elaborou um anteprojeto de lei que poderia ter promovido a descriminalização do aborto; aprovou a Lei Maria da Penha, que mudou a cara da violência contra a mulher; como diretora da F. Ford no Brasil, apoiou projetos feministas fundamentais para a política de emancipação das mulheres. Aprendi, com o trabalho de luto, que prefiro saudar a grandeza da vida daqueles que partiram e deixaram um pedaço de sua existência em nós. Foi o que fez Nilcéa.

A trajetória de Nilcéa Freire, a grandeza de sua vida, sua atuação na Secretaria de Políticas Para Mulheres (SPM), hoje desconstruída, deverá ser alvo de nossas memórias e reflexões coletivas no Seminário Internacional Fazendo Gênero 12, em julho de 2020.

\section{Referências}

BASILIO, Ana Luiza. "Congresso derruba veto de Bolsonaro e escolas públicas terão psicólogos". Carta Capital, 27/1 1/2019. Disponível em https://www.cartacapital.com.br/educacao/congressoderruba-veto-de-bolsonaro-e-escolas-publicas-terao-psicologos/. Acesso em 05/1 2/2019.

CARTA CAPITAL. "Tragédia em São Paulo: quem eram os jovens mortos em Paraisópolis". Carta Capital, 02/12/2019. Disponível em https://www.cartacapital.com.br/sociedade/tragedia-em-saopaulo-quem-eram-os-jovens-mortos-em-paraisopolis/. Acesso em 04/12/2019.

DINIZ, Debora; CARINO, Giselle. “'O estuprador é você', a catarse das meninas chilenas”. El País Brasil, 05/12/2019. Disponível em https://brasil.elpais.com/opiniao/2019-12-05/o-estuprador-e-voceas-meninas-chilenas.html. Acesso em 05/12/2019.

LAGO, Mara C. de S.; RAMOS, Tânia R. O.; MINELLA, Luzinete S.; WOLFF, Cristina S. "Difícil falar do agora". Revista Estudos Feministas, Florianópolis, v. 27, n. 2, e65596, 2019. DOI: 10.1590/18069584-2019v27n265596.

MACEDO, Fausto; ORTEGA, Pepita. Promotoria do Rio denuncia PM pela morte de Ágatha, 8. In: MACEDO, Fausto. "Blog". Estadão, 03/12/2019. Disponível em https://politica.estadao.com.br/blogs/ fausto-macedo/promotoria-do-rio-denuncia-pm-pela-morte-de-agatha-8/. Acesso em 04/12/2019.

NETTO, Paulo Roberto. Juiz suspende nomeação de Sérgio Camargo para presidência da Fundação Palmares. In: MACEDO, Fausto. "Blog". Estadão, 04/12/2019. Disponível em https:// politica.estadao.com.br/blogs/fausto-macedo/juiz-anula-nomeacao-de-sergio-camargo-parapresidencia-da-fundacao-palmares/. Acesso em 05/12/2019.

ONU MULHERES BRASIL. 16 Dias de Ativismo pelo Fim da Violência contra as Mulheres: 2019. Disponível em http://www.onumulheres.org.br/16dias/. Acesso em 03/12/2019.

RODRIGUES, Carla. Recuperado do perfil de Carla Rodrigues. Facebook. https://www.facebook.com/ rodrigues.carla, 29/12/2019. Acesso em 20/01/2020.

VARGAS, Mateus. "Reitores vão à Justiça para que Weintraub prove 'plantação de maconha' nas federais". Correio 24 Horas, 05/12/2019. Disponível em https://www.correio24horas.com.br/noticia/ nid/reitores-vao-a-justica-para-que-weintraub-prove-plantacao-de-maconha-nas-federais/. Acesso em 05/12/2019.

WETERMAN, Daniel. "Congresso já derrubou nove medidas provisórias de Bolsonaro". Estadão, 23/ 11/2019. Disponível em https://politica.estadao.com.br/noticias/geral,congresso-ja-derrubou-novemedidas-provisorias-de-bolsonaro,70003099551. Acesso em 01/12/2019.

Luzinete Simões Minella (simoesluzinete@gmail.com) é doutora em Sociologia pela Universidad Nacional Autónoma de Mexico (UNAM, 1989), graduada (1972) e mestre (1977) em Ciências Sociais pela UFBA. Realizou estágio de Pós-Doutorado no Núcleo de Estudos de População da Universidade Estadual de Campinas (NEPO/Unicamp, 1998). Atualmente é Professora Adjunta IV aposentada da Universidade Federal de Santa Catarina (UFSC), atuando como professora voluntária no PPG Interdisciplinar em Ciências Humanas, onde coordena a área de Estudos de Gênero. Integra a equipe do Instituto de Estudos de Gênero (IEG), participando de vários dos seus projetos (eventos, publicações, cursos etc.). Publicou vários artigos em periódicos de ampla circulação, 
livros, trabalhos completos em anais de eventos etc. Assumiu a coordenação editorial da Revista Estudos Feministas entre 2001 e 2004 e entre 2007 e 2008, quando passou a integrar a editoria de artigos. Voltou a fazer parte desta coordenação em dezembro de 2016. É membro da Rede Iberoamericana de Ciencia, Tecnología y Género. Tem realizado pesquisas principalmente nas seguintes áreas: participação das mulheres nas ciências (na interface com a crítica feminista à ciência, aos estudos sociais da ciência e à história da ciência), gênero e saúde reprodutiva, gênero e infância, saúde mental. Orientou trabalhos de conclusão de curso e tem orientado dissertações e teses, principalmente nessas áreas.

Tânia Regina Oliveira Ramos (taniareginaoliveiraramos@gmail.com) é doutora em Literaturas de Língua Portuguesa pela Pontifícia Universidade Católica do Rio de Janeiro. Possui Graduação em Letras pela Universidade Federal de Santa Catarina, Mestrado e Doutorado em Literaturas de Língua Portuguesa pela Pontifícia Universidade Católica do Rio de Janeiro. Atualmente é Professora Titular e coordena o núcleo Literatura e Memória da UFSC, núcleo com projetos aprovados pela FAPESC e CNPq. Faz parte da Coordenação Geral da Revista Estudos Feministas e do Conselho Editorial das revistas UniLetras, Mafuá Ciências e Letras, Literatura Hoje, Signótica e Anuário de Literatura. É professora de Literatura Brasileira e Estudos Literários nos Cursos de Graduação e PósGraduação em Letras e Literatura na UFSC. Atua, pesquisa e publica nas linhas de pesquisa História e Memória, escritas de si e gênero.

Mara Coelho de Souza Lago (maralago07@gmail.com) é doutora em Psicologia da Educação pela Universidade Estadual de Campinas e Professora Emérita da Universidade Federal de Santa Catarina. Possui Graduação em Pedagogia pela Universidade do Estado de Santa Catarina (1967), Mestrado em Antropologia Social pela Universidade Federal de Santa Catarina (1983). Atualmente é Professora Titular aposentada da Universidade Federal de Santa Catarina/ UFSC, atuando como docente voluntária no Programa de Pós-Graduação em Psicologia/ PPGP e no Programa de Pós-Graduação Interdisciplinar em Ciências Humanas/PPGICH. Tem experiência na área de Psicologia, com ênfase em Psicologia Social, atuando principalmente nos temas gênero, gerações, subjetividades, modos de vida, com enfoque interdisciplinar. Participa do Instituto de Estudos de Gênero (IEG/UFSC) e da coordenação editorial da Revista Estudos Feministas.

Cristina Scheibe Wolff (cristiwolff@gmail.com) é doutora em História Social pela Universidade de São Paulo (1998). Possui Graduação em História pela Universidade Federal de Santa Catarina (1988), Mestrado em História pela Pontifícia Universidade Católica de São Paulo (1991). Em 2004/2005 realizou Pós-Doutorado na Université Rennes 2, na França, e entre 2010 e 2011 , no Latin American Studies Center da University of Maryland, em College Park, Estados Unidos da América. Ocupou a Cátedra Fulbright de Estudos Brasileiros na University of Massachusetts em Amherst (set.-dez. 2017) e foi pesquisadora convidada no Laboratoire Arenes - Université Rennes 2 (jan.-jul. 2018). Atualmente é Professora Titular do Departamento de História da Universidade Federal de Santa Catarina. É integrante do Laboratório de Estudos de Gênero e História (LEGH) e do Instituto de Estudos de Gênero da UFSC e uma das coordenadoras editoriais da Revista Estudos Feministas (2006-2009 e 2011 -atual). Foi coordenadora do Programa de Pós-Graduação em História da Universidade Federal de Santa Catarina. Atua ainda no Programa de Pós-Graduação Interdisciplinar em Ciências Humanas e no Mestrado Profissional de Ensino de História. Foi a coordenadora geral do Fazendo Gênero 11 e $13^{\circ}$ Women's Worlds Congress, realizado na UFSC em 2017. Tem experiência na área de História, com ênfase em História das Mulheres e do Gênero, ałuando principalmente nos seguintes temas: gênero, memória, guerrilha, resistência às ditaduras no Cone Sul.

\section{COMO CITAR ESSE ARTIGO DE ACORDO COM AS NORMAS DA REVISTA}

MINELLA, Luzinete Simões; RAMOS, Tânia Regina Oliveira; LAGO, Mara Coelho de Souza; WOLFF, Cristina Scheibe. "Resistindo às pressões dos conservadorismos, apesar de tudo". Revista Estudos Feministas, Florianópolis, v. 28, n. 1, e70610, 2020.

CONTRIBUIÇÃO DE AUTORIA

Elaboração e redação coletiva.

FINANCIAMENTO

Não se aplica. 
LUZINETE S. MINELLA, TÂNIA REGINA O. RAMOS, MARA C. DE S. LAGO E CRISTINA S. WOLFF

\section{CONSENTIMENTO DE USO DE IMAGEM}

Não se aplica.

APROVAÇÃo de COMITÊ de ÉtICA EM PESQUISA

Não se aplica.

CONFLITO DE INTERESSES

Não se aplica.

LICENÇA DE USO

Este artigo está licenciado sob a Licença Creative Commons CC-BY. Com essa licença você pode compartilhar, adaptar, criar para qualquer fim, desde que atribua a autoria da obra.

HISTÓRICO

Recebido em 12/12/2019

Aprovado em 27/01/2020 